\title{
ANTROPOLOGIAA
}

\section{La antropología y la sociología ${ }^{1}$}

Recibido: 04/03/2014

Aprobado: 26/05/2014

Leif Korsbaek ${ }^{2}$

Escuela Nacional de Antropología e Historia, México

<lkorsbaek@hotmail.com>

\begin{abstract}
RESUMEN
En el artículo se sigue el desarrollo de la disciplina de sociología en su carrera histórica, en su permanente convivencia con la vecina disciplina de la antropología: primero los precursores y los padres fundadores, Émile Durkheim, Max Weber y Carlos Marx, que son compartidos entre las dos disciplinas. Luego otro tríptico: los románticos, o sea los neokantianos y antipositivistas, los funcionalistas científicos y los marxistas, que curiosamente coinciden también entre las dos disciplinas. Antes de llegar a la conclusión, en la cual se plantea que la separación de la antropología y la sociología es una separación con pocos fundamentos, se hacen dos excursiones: se presenta una invención que se hizo al mismo tiempo en las dos disciplinas, llamado "antropología cognoscitiva" en una disciplina y "etnometodología" en la otra, y la moda efímera de la posmodernidad, también dividida entre las dos disciplinas.
\end{abstract}

PALABRAS ClAVE: antropología, sociología, interdisciplinariedad, historia de las ciencias

\section{Anthropology and Sociology}

\begin{abstract}
The article begins with an exploration of sociology's historical development, always in close connection with the sister discipline of anthropology, first in the proto sociologists and protoanthropologists, thereafter in the founding fathers, Émile Durkheim, Max Weber and Karl Marx, who are at the same time sociologists and anthropologists. Next comes another scientific triangle: the romantics or neokantians, the scientific functionalists and the Marxists, who curiously coincide in sociology and anthropology as well. Before reaching the conclusion, that suggests that the separation of sociology and anthropology is a separation with an extremely frail foundation, we make two excursions: to an invention that was made at the same time in sociology and anthropology, in the first discipline named "ethnomethodology", and in the second "cognitive anthropology", and the shortlived fashion of postmodernism.
\end{abstract}

KEYWORDS: Anthropology, sociology, interdisciplinary approach, history of science

1 El presente texto, que es un avance hacia un texto que trate sistemáticamente la relación entre la antropología y la sociología, fue presentado originalmente como conferencia en el Departamento de Sociología, Universidad Nacional de Panamá, el 21 de noviembre de 2008 (ya que la antropología es un terreno enorme y la sociología tal vez más enorme todavía, y la relación entre las dos disciplinas es como de una enormidad en segunda potencia, deseo subrayar con mucha fuerza que tiene carácter de un "avance").

2 Profesor-Investigador ENAH-INAH, Antropólogo de la universidad de Copenhague, Doctor en Ciencias Antropológicas por la UAM Iztapalapa. El presente artículo es producto de los cursos de "Corrientes no Antropológicas en la Antropología" que impartí en la Facultad de Antropología de la UAEM en Toluca y en la Licenciatura y la Maestría de Antropología Social de la Escuela Nacional de Antropología e Historia (ENAH). 


\section{Introducción}

E s el objetivo de este texto discutir la relación entre dos de las disciplinas más estrechamente relacionadas de las llamadas ciencias sociales: la antropología y la sociología. Sin embargo, por un número de razones es difícil discutir la relación entre estas dos disciplinas.

Por un lado debido a su cercanía mutua. "Hay solo un vecino con el que la sociología no tiene una frontera precisa: la etnologia", señala Timasheff en un libro ya clásico de la sociología (Timasheff, 1992: 22). En algunos momentos se ha borrado casi por completo la distancia y la diferencia, como cuando RadcliffeBrown define la antropología social como "sociología comparativa”, mientras que otro gurú sociológico en la Universidad de Copenhague introdujo el concepto de "sociología cultural", teniendo en mente que uno de los rasgos distintivos de la antropología es que su concepto fundamental es el concepto de "cultura", a diferencia de otras disciplinas.

Por otro lado, ambas disciplinas presentan en su carrera histórica una asombrosa riqueza de formas, estilos y definiciones, hasta tal grado que se puede llegar a tener desconfianza en su identidad ${ }^{3}$. En varias ocasiones se ha presentado la riqueza de definiciones de la antropología y, como un preámbulo a la discusión aquí prometida, en el siguiente apartado se hace un recorrido por la variación y variabilidad histórica de la sociología y de la antropología en cuanto disciplinas más o menos académicas en lo que podemos llamar su prehistoria, seguida por los esfuerzos de los padres fundadores por definir su invento.

Como en los demás textos de esta serie, es mi opinión que no es posible entender la dinámica de las diferentes disciplinas sin tomar en cuenta el proceso histórico que las ha producido y en la producción de la cual las mismas disciplinas al mismo tiempo participan activamente. En los demás textos he declarado que "la mirada es antropológica", lo que es también el caso con este texto, sin embargo, debido a la cercanía de la sociología y la antropología, la mirada es en este caso tanto sociológica como antropológica (Korsbaek, 1999).

El presente texto parte de la hipótesis de que las dos disciplinas, la antropología y la sociología, en su desa-

3 Es interesante que, mientras que la antropología en la tradición europea definitivamente surge de la sociología, igual que el caso en Cuba (Korsbaek \& Barrios, 2010), en México es al revés: la sociología mexicana nace a partir de la antropología. rrollo histórico representen una misma visión del mundo - hasta tienen un mismo origen, ambas disciplinas nacieron desde la filosofía, y sus divisiones internas en la sociología se reconocen en la antropología — solamente con la diferencia de que la antropología pone su énfasis en la heterogeneidad y una visión inclusiva que abarca sistemáticamente la alteridad, mientras que la sociología tiende a enfatizar una relativa homogeneidad, limitándose al mundo occidental y excluyendo la alteridad.

\section{La prehistoria de la sociología y la antropología}

Es sabido que tanto la antropología como la sociología provienen en cuanto disciplinas de la filosofía, de la cual se separaron en diferentes momentos y de maneras también diferentes, por lo que tenemos que buscar su prehistoria en esta disciplina, más precisamente en lo que en su momento se llamaba filosofía social.

Sin embargo, quisiera introducir dos instancias de lo que podemos llamar "pensamiento sociológico" en la temprana historia colonial del mundo hispanohablante, México, en aquel entonces todavía la Nueva España y la vieja España.

Tenemos las Relaciones geográficas de Felipe II, que representan un uso muy temprano del cuestionario, con 37 preguntas, y que comparten tal vez un rasgo más con mucha investigación antropológica y sociológica (y de otras disciplinas): terminaron en un cajón y nunca fueron utilizadas ${ }^{4}$, solamente mucho más tarde un historiador metiche las sacó de su basurero.

Y tenemos, un poco más tarde, la hermosa novela El diablo cojuelo de Luis Vélez Guevara que, según su hijo nació "en Écija a 26 de agosto de 1578, fue hijo de Diego Vélez de Guevara y de Dońa Francisca Negrete de Santander", fue bautizado en la Parroquia de San Juan de dicho lugar, con indicación de "sábado primero día del mes de agosto, año de mil y quinientos y setenta y nueve años, bapticé yo, el Bachiller Alonso Navajas ... a Luis", ... y "murió dejando muchas esperanzas de su salvación, de unas calenturas maliciosas y un aprieto de orina a 10 de noviembre, año de 1644" (Carta de Juan Vélez, hijo del novelista, citada en Rodríguez Cepeda, 1990: 13).

La justificación de llamar esta novela "precursor del pensamiento sociológico" es el recurso que desarrolla el

4 Nos recuerda lo dicho por los antropólogos británicos acerca de su gobierno: el gobierno británico usa la antropología como el borracho un poste de luz: no para iluminarse, sino para apoyarse. 
autor para lograr una objetivización de sus observaciones: monta al diablo a un palo de escoba para permitirle volar por encima de los techos de la ciudad y observar lo inobservable: la vida privada de la gente. Así que no es injusto considerar al diablo en esta versión como el iniciador de lo que posteriormente se llamaría la "etnología de la alcoba" (Dibie, 1999).

Podemos acercarnos a una distinción entre la sociología y la antropología, ya en esta temprana etapa, si incluimos en nuestra discusión a los cronistas en la entonces Nueva España: Bernal Díaz del Castillo, Bernardino de Sahagún, Bartolomé de las Casas, Alva Ixtlilchóxitl, Garcilaso de la Vega y Guaman Poma, entre los más conocidos.

Si nos dirigimos a la ilustración del siglo XviII encontramos heroicos intentos por analizar y comprender el proceso histórico, y podemos buscar precursores de los sociólogos entre los llamados historiadores universales, los cuales podemos considerar como precursores de la teoría marxista de la historia y de la sociedad: Voltaire, Rousseau, Diderot, d'Alembert, entre los franceses, David Hume, John Millar, Adam Smith, Adam Ferguson, Richard Robertson, entre los escoceses. Entre los inventos conceptuales más importantes de los ilustrados tenemos la civilización y el progreso, este último concepto fue formulado por Buffon y Condorcet, entre otros, y luego perfeccionado a ser el concepto de evolución, el concepto medular de la temprana ciencia social que es al mismo tiempo antropología, sociología e historia, incluyendo también a la prehistoria y la arqueología y en colindancia con la geología.

De manera inmediata y poco crítica podemos buscar el origen tanto de la antropología como de la sociología en la filosofía, en una epidemia de especialización y fragmentación del proceso de producción de conocimientos científicos en los momentos iniciales del positivismo, en la segunda mitad del siglo XIX. La antropología se salió del corral filosófico para nuclearse en una nueva disciplina antropológica, el evolucionismo decimonónico por todos conocido, a través de sus estrellas más o menos fugaces: Morgan, Maine, McLennan, Marx, Bachofen, Fustel de Coulanges, Spencer, Galton y Lubbock entre otros muchos. De la misma manera es sabido que la sociología -curiosa criatura compuesta de lo "socio" del latín y de la "logia" del griego- es invento conceptual de Augusto Comte, también desde la filosofía y también al inicio del mismo período histórico, dentro de la misma corriente positivista.
Brilla una serie de nombres ilustres en este período: Herbert Spencer, el iniciador del pensamiento evolucionista y un notable, y el primero en usar la expresión evolucionismo, y Francis Galton, primo de Charles Darwin.

Un daño duradero fue la formulación de la eugenesia, la idea de que se pueda llegar a una purificación racial a través de la selección, una teoría que sería aprovechada por pensadores poco pensativos como Adolf Hitler y, más recientemente, fundamentalistas religiosos en los Estados Unidos. Esta innovación se tiene que ver en conjunto con la operacionalización de la teoría en el taller de la antropometría, inaugurado durante la Exposición Internacional de la Salud en 1884 en Londres, que seguía funcionando hasta 1890 , produciendo abundancia de datos cuantitativos; "la práctica de eugenesia se reflejó en la limpieza étnica, así como en la esterilización de personas con discapacidad intelectual, delincuentes, pobres o enfermos mentales" (Wikipedia). Un desarrollo posterior sería la teoría determinista de Cesare Lombroso, definiendo al típico delincuente con rasgos que curiosamente coinciden con los rasgos de los típicos mexicanos y los típicos peruanos.

Sigue John Lubbock, que tuvo la suerte de ser hijo de un banquero, que además era barón, e hizo popular el término prehistoria (que ciertamente ya había sido introducido en 1851).

En todos los ambientes del evolucionismo podemos buscar un enemigo común, pues todo este proceso de avance y maduración científicos se llevó a cabo en una permanente lucha contra la iglesia, en sus lugares católica, en Inglaterra la anglicana, en menor grado contra la iglesia luterana. En Inglaterra, de acuerdo con el temido y temible Calendario Ussher-Lightfoot, era posible calcular, a partir de las escrituras sagradas, que el nacimiento de la tierra hubiera sucedido el año 4004 a. D. C., y que la creación había tomado lugar exactamente el 23 de octubre a las 9 de la mañana 5 , y aun en 1825 Georges Cuvier, uno de los descubridores de los dinosaurios, justificaba la presencia de restos de hombres primitivos como una consecuencia "del Diluvio Universal que había provocado que la civilización humana degenerase hacia el salvajismo" (Cuvier, 1825, p. 147).

5 Formulado por James Ussher, arzobispo de Armagh, y el vicerrector de la Universidad de Cambridge, John Lightfoot; véase James Ussher: "Annals of the Ancient and New Testaments", Londres, 1650 (existe reedición moderna de 2003); John Lightfoot: "A Few and New Observations on the Book of Genesis, the most of them certain, the rest probable, all harmless strange and rarely heard of before", Londres, 1642. 
Podemos buscar elementos compartidos y diferencias significativas entre la prehistoria antropológica y la de la sociología, pero creo que la única diferencia significativa entre las dos prehistorias es la respectiva presencia y ausencia de la alteridad, y eso con un grano de sal; las dos disciplinas sencillamente todavía no se habían definido y diferenciado.

Dejando atrás a los precursores, podemos decir que las dos disciplinas empiezan a perfilarse como ciencias en su propio derecho y con sus propias definiciones en la segunda mitad del siglo xIx, con variaciones y algo de inseguridad: la sociología fue bautizada en 1839, por Augusto Comte, mientras que la antropología científica supuestamente nació entre 1861 y 1891. En el caso de la sociología, Augusto Comte merece un lugar como padre de la sociología, por haber bautizado esta nueva disciplina, sin embargo podemos buscar fundamentos más sólidos en el pensamiento de Saint-Simon, de quien Comte fue secretario, y una institucionalización más acabada en algunos de sus seguidores. En el caso de la antropología, vemos una impresionante producción de libros seminales exactamente en 1861 - El matriarcado del abogado suizo Bachofen, El derecho antiguo de Sir Henry Maine y un curioso libro de Edward B. Tylor, Anahuac, or Mexico and the Mexicans, Ancient and Modern-, una oleada que continuaría en los siguientes años.

\section{Los padres fundadores}

De la iglesia católica las ciencias sociales han heredado la expresión los padres fundadores, y casi siempre se hace referencia al trío dinámico de Émile Durkheim, Max Weber y Karl Marx. Conviene señalar que aparentemente fundaron las disciplinas en conjunto, antes de la separación de la antropología y la sociología, más bien en el momento de su separación de la filosofía, así que si aceptamos a los tres como fundadores de la sociología, entonces vemos que los tres son al mismo tiempo también, en el mismo período pero de diferentes maneras, los padres fundadores de la antropología.

Emile Durkheim es el indiscutible padre de un estilo positivista de hacer sociología, su formación es de filósofo, pero le da cuerpo a la ciencia de la sociología que Auguste Comte ya había bautizado y cuyos fundamentos ya habían sido delineados por Saint-Simon, y en 1887 imparte, a su nombramiento de profesor de pedagogía y ciencia social en la Universidad de Bur- deos, los primeros cursos de sociología en Francia, cursos que repetirá en 1890, 1900, 1904, 1912 y 1917, inmediatamente antes de su muerte. Al inicio de su período de Burdeos obtiene su grado de doctor con una tesis acerca de "La división del trabajo social", y una tesis secundaria en latín acerca de "Montesquieu". En su tesis introduce una exigencia de solidaridad, y hace una distinción entre dos tipos de solidaridad: la solidaridad mecánica y la solidaridad orgánica, y luego escribe y publica un pequeño libro que es en verdad el marco teórico de su tesis, en una forma más comprimida y en un lenguaje más programático y contestatario: Las reglas del método sociológico, que parte de la observación de que "hasta el día de hoy los sociólogos no le han prestado mucha atención a la tarea de caracterizar y definir el método que aplican al estudio de los hechos sociales" (González, 1988: 9, 15, 20) y que en seis capítulos apretados plantea y discute igual número de problemas urgentes en su programa sociológico. Una de las contribuciones trascendentales de Durkheim al pensamiento sociológico (y antropológico), que ocupa el capítulo 1 de su librito, es la formulación del concepto del hecho social — pues, "antes de buscar cuál es el método adecuado para el estudio de los hechos sociales conviene saber cuáles son los hechos así llamados" (p. 56), en sí toda una pequeña declaración positivista- ya que "en realidad, en toda sociedad hay un determinado grupo de fenómenos que se distinguen por caracteres precisos de aquellos que estudian las otras ciencias de la naturaleza" (González, 1988: 9, $15,20)$. El hecho social se destaca con sus tres características: es exterior, obligatorio o coercitivo, y general o independiente (p. 69). El hecho social es exterior en el sentido de que le precede al individuo: "estos tipos de conducta o de pensamiento no solo son exteriores al individuo, sino que están dotados de un poder imperativo o coercitivo en virtud del cual se imponen a él, lo quiera o no" (p. 57). De las reglas relativas a la observación de los hechos sociales, que llenan el capítulo dos de su librito, "la primera regla, y la de carácter más fundamental, es la de considerar a los hechos sociales como cosas" (Durkheim, 1988: 53). La pequeña obra de Durkheim con el alegre título El suicidio fue publicado en 1897, contiene antes que nada una tipología del suicidio y una sistematización de las conclusiones que se pueden sacar, es decir que es netamente una obra metodológica.

En 1896 planea, junto con algunos seguidores, la revista l'Année Sociologique cuyo primer número será 
publicado en 1898. La revista tenía por objetivo ofrecer anualmente un informe acerca de la literatura estrictamente sociológica, pero debía ofrecer también, citando de la introducción al primer número, "información regular sobre los estudios que se están llevando a cabo en ciencias concretas - historia del derecho, de la cultura y de la religión, estadística moral, economía, etc.- puesto que son estas ciencias concretas las que proporcionan el material con el que debe construirse la sociología”, y además artículos originales que contribuiría a la construcción de la sociología, como lo visualizaba Durkheim. La revista fue planeada como un foro abierto, pero con el tiempo la revista "se fue haciendo más durkheimiana y menos ecléctica” (Lukes, 1984: 293).

Una fuerte obsesión de Durkheim, a través de toda su vida, fue la normatividad, y es interesante constatar el número elevado de artículos y, en particular de reseñas, que dedica al estudio del fenómeno legal. De igual manera, desde 1898 su revista l'Année Sociologique está también repleta de artículos y reseńas relacionados con diversos aspectos de la ley, el derecho y la criminología ${ }^{6}$.

Hacia el final de su vida pública otra obra seminal, Las formas elementales de la vida religiosa, donde plantea su postulado de la universalidad de la religión, y la idea de que existe universalmente una distinción entre lo profano y lo sagrado. Es curioso que Émile Durkheim, probablemente el que más fuertemente ha alegado la necesaria universalidad de la religión, en lo personal era totalmente ateo y agnóstico, dedicándose por completo al método científico para la adquisición y verificación de conocimientos (lo que curiosamente vale también para el otro que podemos llamar el sociólogo más importante del estudio sociológico de la religión, Max Weber; y quien tenga ganas puede agregar también a Carlos Marx como un destacado estudioso del fenómeno religioso que de ninguna manera era religioso en lo personal).

Max Weber es también de manera indiscutible el padre de un estilo antipositivista de hacer sociología, que tiene una larga trayectoria. La producción literaria de Max Weber es relativamente modesta, lo que con-

6 La primera manifestación de esta obsesión la encontramos ya en 1889, cuando publica en la revista Revue Philosophique una reseńa de un libro (en alemán) de W. Lutoslawski acerca del destino de las constituciones después de Platón, Aristóteles y Maquiavelo, y en 1895 sigue, en la misma revista, un artículo acerca de "el crimen y la santidad social", y en 1901 una reseña del libro "La Tradition Romaine sur la Succession” de E. Lampert. trasta notablemente con el volumen de libros y artículos dedicados a discutir su obra y su posición (la "guerra académica de cien años") 7 . Como en muchos casos de antaño (y de hoy), no se sabe exactamente cómo etiquetar a Max Weber: recientemente se escribió que "si en la actualidad preguntásemos en el marco universitario español dentro de qué estudios habría que situar a Max Weber, es muy probable que la mayoría (de los que, al menos, lo conocieran de nombre) lo ubicase dentro de la sociología y, a buen seguro, el resto se repartiría entre aquellos que lo incluyesen en estudios de la filosofía del derecho o de historia económica"8. Se puede ver como historiador, sobre todo historiador económico, se puede ver como sociólogo y y se puede ver como un filósofo que se especializa en cuestiones de metodología ${ }^{10}$, y si alguien tiene ganas, creo que no sería difícil tampoco verlo como politólogo. Finalmente lo podemos ver como político, fuertemente enquistado en el nacionalismo alemán de su día ${ }^{11}$.

En la agenda de hoy encontramos una intensa revisión del pensamiento de Max Weber, como ejemplo se puede mencionar un punto específico, entre los doce puntos menciona Francisco Gil Villegas, como el punto 3 , que

al escribir sus ensayos sobre la ética protestante, Max Weber no tenía como propósito ni refutar a Marx ni sustituir, como nos lo advierte explícitamente en el último párrafo de sus ensayos, una interpretación causal, unilateralmente materialista de la cultura y

7 La persona de Max Weber parece ser una fuente inagotable de fascinación, y los retratos y biografías de él abundan. Dos de los más accesibles, pero muy personales, son el psicoanálisis de Arthur Mitzman (1976) y la monumental biografía de su viuda (Marianne Weber, 1995), que es todo un alegato feminista; menos personales y más dirigidas hacia su posición académica y teórica son la semblanza de Raymond Aron (1976, II: 219-316) y de Reinhard Bendix (1970; el autor había nacido en Berlín en 1916, así que la historia de Alemania y de sus tradiciones científicas y filosóficas le eran familiares, pero emigró ("escapó") en 1942 a los Estados Unidos).

8 Piedras Monroy, 2004: 9.

9 Creo que las dos obras más conocidas de Max Weber, La ética protestante y el espiritu del capitalismo (Max Weber, 2003) y Economía y sociedad (Max Weber, 1964) más bien lo colocan en el campo de la sociología (es curioso que ambos libros son, en su forma actual, ediciones póstumas).

10 Podemos verlo como un filósofo especializándose en cuestiones metodológicas, por ejemplo en una antología que reúne a cuatro de sus ensayos: "La objetividad cognoscitiva de la ciencia social y de la política social" de 1904, "Estudios críticos sobre la lógica de las ciencias de la cultura" de 1906, "Sobre algunas categorías de la sociología contemporánea" de 1913 y "El sentido de la neutralidad valorativa de las ciencias sociológicas y económicas" de 1917 (reunidos en Max Weber, 2001).

11 Sus ensayos políticos han sido reunidos en español en el librito Escritos politicos (Max Weber, 1991). 
de la historia por otra espiritualista igualmente unilateral. Ambas son igualmente imposibles. Pero con ambas se haría el mismo flaco servicio a la verdad histórica si se pretendiera con ellas, no iniciar la investigación, sino darla por concluida ${ }^{12}$.

La visión sistémica de Durkheim no le deja mucho espacio al individuo, a lo que Max Weber se opone y nos presenta una visión científica que coloca al individuo en la primera línea, hasta tal grado que podemos verlo como uno de los iniciadores del individualismo metodológico que en ańos recientes se ha hecho tan importante. Un monumento a Max Weber y su individualismo metodológico lo encontramos en un pequeño libro del filósofo Peter Winch, en el cual el autor es más weberiano que Max Weber himself. El libro causó en su momento, en 1958, una fuerte polémica y lo podemos llamar el libro fundamental del individualismo extre$\mathrm{mo}^{13}$.

Con su privilegiada atención al individuo, para Max Weber la racionalidad (uno de sus principales intereses) es exclusivamente la racionalidad del individuo (o, más precisamente, del agente), y no como en la obra de Maurice Godelier, la relación dialéctica entre la racionalidad del individuo y la del sistema ${ }^{14}$.

En sus estudios de los tipos de dominación ${ }^{15}$ distingue entre tres tipos diversos: la dominación legal con administración burocrática, la dominación tradicional y la dominación carismática, una tipología que en su secuencia lógica es claramente evolucionista, y desarrolla el concepto de tipos ideales de ser una herramienta histórica a ser una herramienta netamente sociológica ${ }^{16}$.

Por supuesto tenemos problemas para colocar a Marx como padre de una sociología marxista, pero sí podemos nombrarlo padre de una sociología dialéctica, y es de por sí una sociología con una clara posición política. El período que atestigua las actividades de los que hemos nombrado los padres fundadores coincide con el colonialismo, el nacionalismo y la revolución industrial, lo que coloca forzosamente a nuestros tres padres en una posición política Podríamos tal vez ver una manifestación simbólica de nuestros padres en el hecho de que en 1918, en Versalles, en las negociaciones de la paz después de la Primera Guerra Mun-

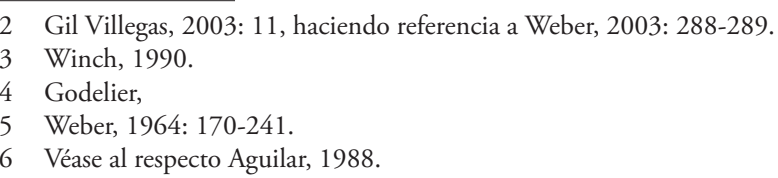

dial se enfrentan dos notables científicos: Max Weber como representante de la Alemania que perdió la guerra, y John Maynard Keynes, importante economista, en representación de los aliados que habían ganado la guerra. Los dos están en Versalles en representación de sus respectivas naciones y estados pero, lo que es tal vez más importante, están allá en representación de sus burguesías, y es claro que en aquellas mesas nadie representaba a los obreros.

Pero, regresando al período histórico de los padres fundadores, es claro también que en aquel momento todavía no se ha cristalizado una separación de la antropología y la sociología; de una manera muy complicada, las dos disciplinas se adhieren sin titubeo a la teoría evolucionista: Marx de una manera clara y sin ambigüedad, Max Weber en el desfile de sus modos de dominación — tradicional, carismático y racionalburocrático- que van de lo más primitivo hacia lo más avanzado, Durkheim en la dicotomía que separa la solidaridad mecánica de la orgánica.

En este ambiente generalizadamente evolucionista podemos ya encontrar los primeros pasos de Carlos Marx hacia un pensamiento sociológico en algunas de sus obras de juventud.

Los tres grandes aquí mencionados son los padres fundadores universal y formalmente reconocidos, pero quisiera agregar a uno más que nunca recibe la merecida atención y los créditos ampliamente ganados: un tal Frederic LePlay, conocido también como el Marx de la burguesía. Frederic LePlay era ingeniero minero y es curioso que haya tenido una influencia tan profunda sobre la sociología y la antropología, sin que nadie se haya dado cuenta.

\section{Las dos disciplinas en su madurez: la vía romántica}

Fue Coleridge quien dijo que "cada hombre nace como aristotélico o como platónico”, y lo mismo sucede en el caso de las ciencias sociales, donde, hasta cierto grado, el Atlántico se encarga de separar a los aristotélicos de los platónicos, por lo menos en la antropología. Lo platónico podemos reconocer en el pensamiento de Max Weber y sus seguidores, así como sus antecesores, pero tenemos que ir un poco atrás y localizar por lo menos tres momentos anteriores a la entrada de Max Weber al escenario.

Primero, tenemos que tomar en cuenta toda una tradición de filosofía pesimista en Alemania: podemos 
empezar con el pensamiento de Schopenhauer, que pone el énfasis en la voluntad, percibiendo "el mundo como voluntad y representación", creando así un mundo de pensamiento subjetivo y voluntarista. El pensamiento de Friedrich Nietzsche no es menos subjetivo y pone igual, o mayor, énfasis en la voluntad. Finalmente tenemos la expresión más explícita en las ideas de Oswald Spengler en La decadencia del Occidente. Bosquejo de morfología de la historia universal (Spengler, I: 1918, II; 1922, 1978).

Segundo, tanto en la antropología como en la sociología contamos con un continuo esfuerzo por captar lo subjetivo, una tradición cuyo origen se puede buscar en el pensamiento de Kant y en sus seguidores más radicales, los neokantianos. El movimiento empezó en la filosofía: en 1865 publicó el joven filósofo alemán Otto Liebmann un pequeño libro con el título nada ambiguo Kant und die Epigonen (Kant y los epígonos), en el cual cada capítulo terminó con la conclusión: "así que tenemos que regresar a Kant". A partir del libro de Otto Liebmann se desarrolló un movimiento neokantiano, antipositivista, que absorbió algunas de las posiciones pesimistas de Nietzsche y Ostwald, y llegó a su máximo desarrollo en las escuelas de Marburg y Heidelberg, representadas en las obras de Rickert y Windelband. Uno de los puntos principales en esta orientación fue la separación de las ciencias naturales, que exigían un conjunto de leyes naturales ahistóricas que llevarían hacia la explicación de los fenómenos, buscando verdades objetivas y haciendo a un lado cualquier lengua que no fuera la de las matemáticas, hacia una comprensión de lo históricamente específico que se busca en las ciencias del espíritu ("Geisteswissenschaften").

Tercero, en relación con esta filosofía (que es realmente en ciertos aspectos una continuación del romanticismo) desarrolla Edmund Husserl su fenomenología que pretende ser una ciencia estricta ("strenge Wissenschaft"), que desemboca en un estudio de la crisis de la cultura y de la ciencia occidentales, desarrollando su herramienta conceptual "mundo de vida" ("Lebenswelt").

$\mathrm{Y}$ aquí entra la actividad taumatúrgica de Max Weber, pero lo tenemos que ver en su relación con la principal ola neokantiana en la antropología, que tiene su inicio en 1887, en la frontera entre Alemania y los Estados Unidos, en la persona de Franz Boas.

En la sociología podemos discernir toda una tradición que tiene sus raíces y sus fundamentos teóri- cos y metodológicos en el pensamiento filosófico de Edmund Husserl y en el pensamiento sociológico de Georg Simmel, más o menos contemporáneo de Max Weber son Georg Simmel y Ferdinand Tönnies, una tradición que se manifiesta como fuertemente antipositivista y de inclinación fenomenológica.

Podemos localizar tres fechas medulares en el pensamiento sociológico de Simmel: 1894, cuando formula las cuestiones fundamentales de la sociología, 1908 cuando publica su "sociología grande" y 1917 cuando publica su "pequeña sociología". Realmente, encontramos a su sociología encerrada entre su "sociología grande" de 1908 y su "pequeña sociología" de 1917, solamente un año antes de su muerte en su exilio cultural en Strassbourg. De los múltiples intentos de Simmel por definir la nueva ciencia de la sociología se desprenden dos rasgos de su definición de esta disciplina: primero que no es una ciencia substantivamente definida y, segundo que, a pesar de eso no es una ciencia formal. A diferencia de Émile Durkheim, "la sociología de Simmel no se basa en un nuevo objeto material sino en un objeto formal, un nuevo modo de observación, un punto de vista, una abstracción" (Steinhoff, 1924-25: 228-229).

Un momento importante en este proceso histórico es cuando estos tres pensadores alemanes - Max Weber, Georg Simmel y Ferdinand Tönnies - en 1909 fundan la Sociedad Alemana de Sociología ("Deutsche Gesellschaft für Soziologie"). Resumiendo, acerca de uno de estos antipositivistas, "se podría decir que la filosofía de Alfred Schutz articula una sola intuición: el descubrimiento, en su cabal profundidad, de las presuposiciones, estructura y significación del mundo del sentido común" (Natanson, 1995: 15).

El mismo Alfred Schutz formula así los fundamentos de su sociología haciendo referencia a la inspiración de William James, John Dewey, Bergson y Edmund Huserl, pero antes que nada a Alfred North Whitehead: "Todo nuestro conocimiento del mundo, tanto en el sentido común como en el pensamiento científico, supone abstracciones, es decir, conjuntos de abstracciones, generalizaciones, formalizaciones e idealizaciones propias del nivel respectivo de organización del pensamiento. En términos estrictos, los hechos puros y simples no existen. Desde un primer momento todo hecho es un hecho extraído de un contexto universal por la actividad de nuestra mente. Por consiguiente, se trata siempre de hechos interpretados, ya sea que se los considere separados de su contexto mediante una abs- 
tracción artificial, o bien insertos en él. En uno u otro caso, llevan consigo su horizonte interpretativo interno y externo. Esto no significa que en la vida diaria o en la ciencia seamos incapaces de captar la realidad del mundo, sino que captamos solamente ciertos aspectos de ella: los que nos interesan para vivir o desde el punto de vista de un conjunto de reglas de procedimiento aceptadas para el pensar, a las que se denomina método científico" (Schutz, 1953: 36-37).

Los continuadores más fieles en la sociología se mueven a través de las ideas de Max Weber y la fenomenología de Husserl, una fenomenología que encontró su expresión en los seguidores de Schutz, como Berger y Luckman, en la antropología se concentran dentro de la antropología cultural, nítidamente separados de la antropología social británica. Como en cualquier intento por encasillar las diferentes escuelas y tendencias, siempre habrá traslapes y casos difícilmente encasillables.

\section{Las dos disciplinas en su madurez: la vía científica}

Uno de los detalles interesantes en la sociología de Durkheim es tal vez que en algún momento será secuestrado por el antropólogo social británica Radcliffe-Brown y utilizado para apuntalar a la antropología social británico, de afiliación positivista. Los padres fundadores de la sociología se inscriben en un período histórico cuando la alteridad se nos ofrece no como exotismo sino como un cuerno de la abundancia explotable, y el método de explotación de este cuerno es el colonialismo. La antropología se separa parcialmente de la sociología debido a la relación diferencial con la alteridad.

Bronislaw Kaspar Malinowski, uno de los dos fundadores de la antropología funcionalista en Inglaterra, nació en 1884 en la ciudad Krakow en Polonia, hijo de un conocido lingüista, especialista en lenguas eslavas, hizo sus primeros estudios en la escuela pública y luego estudió en la universidad en la misma ciudad, donde obtuvo su doctorado en ciencias naturales (física y matemáticas) en 1908. Como cualquier otra orientación o escuela científica, la de Malinowski es una melcocha: "Evolucionismo, difusionismo, psicología de William James, sociología durkheimiana, psicoanálisis: he aquí, citada de manera informal, las principales fuentes de influencia que utilizará Malinowski en su intento de encontrar su propio camino" (Panoff, 1974: 20-21).
El tono general de la antropología de Malinowski lo encontramos en una larga declaración programática de sus Argonautas, donde toma distancia tanto de los evolucionistas como de los difusionistas: "Me parece que hay lugar para un nuevo tipo de teoría. La sucesión en el tiempo y la influencia de la etapa anterior sobre la posterior es el principal objetivo de los estudios evolucionistas, tal como los practica la escuela clásica de la antropología inglesa (Tylor, Frazer, Westermarck, Sydney Hartland, Crawley). La escuela etnológica (Ratzel, Foy, Gräbner, W. Schmidt, Rivers y Eliot-Smith) estudia la influencia de las culturas por contacto, infiltración y transmisión. La influencia del medio ambiente sobre las instituciones culturales y la raza lo estudia la antropogeografía (Ratzel y otros). La influencia mutua de los distintos aspectos de una institución, el estudio del mecanismo social y psicológico en el que se basa una institución, constituyen un tipo de estudios teóricos que hasta ahora sólo se han practicado de forma ensayística, pero me arriesgo a predecir que tarde o temprano tendrán el reconocimiento que merecen. Este tipo de investigación abrirá el camino y proporcionará los materiales para las otras" (Malinowski, 1975: 503). De este pasaje se desprende que la antropología de Malinowski se fundamenta en el estudio de la interacción de las diferentes instituciones y sus aspectos en su armonioso afán de satisfacer las necesidades del hombre,

Sin embargo, a diferencia de la antropología de Radcliffe-Brown, la antropología de Malinowski no es una antropología intemporalmente anclada en el eterno presente etnográfico, sino una antropología de proceso y de compromiso.

Podemos utilizar como guía dos declaraciones del alumno más allegado a Malinowski, Raymond Firth, que por cierto era economista de formación, por un lado que "los conocimientos teóricos que tenía Malinowski provenían más del grupo de los que en sentido amplio se podrían llamar sociólogos que de los economistas propiamente dichos, con los que nunca tuvo demasiado contacto" (Firth, 1974: 227) y, por otro, que "nunca llegó a presentar el material que había reunido en las Trobriand bajo la forma de una exposición ordenada y completa del sistema económico de la comunidad, y en cambio en esta obra y en las anteriores sí que presentó por primera vez una importante institución económica primitiva como una "empresa en marcha” y la relacionó íntimamente con la estructura social que le daba su sentido y a la que ella reforzaba" (Firth, 1974: 231). 
Curiosamente, Malinowski prefirió hablar de su "sociología económica" (Malinowski, 1975: 167n) en vez de "antropología económica" (Malinowski, 1912: 82). Y hay algo de ambiguo en su relación con la economía como ciencia y disciplina, pues en momentos opina que la teoría económica es aplicable a lo que él llama el mundo primitivo, en otros momentos se pierde en la riqueza de su propia etnografía que hace muy difícil una comparación. La antropología económica la define como "el estudio de la producción, el cambio, la distribución y el consumo de riquezas" (Malinowski, 1912: 128). Malinowski vuelve a presentarnos a su hombre egoista y calculador, presentándonos "la reciprocidad, las gabelas sistemáticas, la publicidad y la ambición" como "los principales factores del mecanismo compulsivo de la ley primitiva”, y hace una importante observación: que "los alicientes positivos para la observancia de las normas sociales", señalando que "éste es probablemente el aspecto más importante de la teoría funcionalista de la ley primitiva" y que "está en estrecha relación con el hecho de alguna sana realidad biológica, de alguna tendencia de la cultura importante y vinculada a alguna importante función" (Malinowski, 1934: LXVI). Este trabajo coincide en el tiempo con la primera formulación de su teoría general del determinismo cultural en un artículo en la Enciclopedia de las Ciencias Sociales (Malinowski, 1931, discutida en Piddington, 1974), y también aquí se coloca la problemática de la ley en el contexto de esta teoría general: la ley es una de las "necesidades derivadas o instrumentales", cuya satisfacción es en todas las sociedades "tan urgente como los requisitos biológicos para la supervivencia del hombre" (Malinowski, 1934: XXXII).

En uno de sus últimos artículos de 1942, donde Malinowski reseña "The Cheyenne Way: Conflict and Case Law in Primitive Jurisprudence" de Hoebel \& Llewellen (Malinowski, 1942), vuelve al tema y define cuatro tipos de leyes: Ley 1: ley natural, Ley 2: normas sociales, Ley 3: normas sociales y Ley 4: la ley quebrantada. Y finalmente, en otro trabajo póstumo con el título "Freedom and Civilization", un título que nos recuerda el optimismo al final de la Segunda Guerra Mundial, con la fundación de la Organización de las Naciones Unidas y la promulgación de la declaración Universal de los Derechos Humanos (Malinowski, 1947), reduce sus tipos de leyes a dos: ley natural y ley social.

La primera cosa que se puede constatar es que Malinowski desde su particular posición antropológica se mete en un callejón sin salida fácil. Malinowski es positivista y pretende llevar a cabo un estudio científico de la cultura (lo que se desprende de mil declaraciones suyas, y del título: "Una teoría científica de la cultura", 1944), en consecuencia buscando leyes científicas. La complicación surge en el momento de dirigir este estudio científico hacia la problemática de las leyes que inevitablemente resulta en una búsqueda de las leyes científicas que rigen las leyes de la sociedad. ¿Cuál es el relativo estatus y carácter de las leyes científicas y sociales? ¿son iguales, o son diferentes?

Como se señaló, si hacemos caso omiso de lo que podemos llamar la prehistoria de la antropología británica, sus raíces son dos: aparte de Malinowski, el fundador de una antropología cultural de corte biológico, tenemos que tener en mente la contribución de Radcliffe-Brown, el fundador de la tendencia contraria, de una antropología social de corte sociológico y de inspiración durkheimiana. Junto con Evans-Pritchard, alumno suyo, parece que Radcliffe-Brown es casi el único típico británico de clase media en el gremio de los antropólogos, entre inmigrantes polacos, austriacos y de las colonias y los dominios. Nació en un pueblo cerca de Birmingham y se llamaba originalmente Brown, pero con su fama decidió agregar el nombre de su pueblo nativo, Radcliffe, a su apellido con un guión, y se volvió Radcliffe-Brown. Al principio y durante sus estudios tenía contacto con el movimiento anarquista, una tendencia que abandonaría con el tiempo.

Mientras que la labor antropológica de Malinowski era efusiva y entusiasta (y, según Radcliffe-Brown, irresponsable), la mente de Radcliffe-Brown es analítica y su estilo seco, sistemático y coherente. Parte de su lucha fue la elaboración de definiciones de la antropología y tipologías de sus objetos de estudio. Podemos primero echar un vistazo a sus definiciones de la disciplina de antropología social, y luego a algunas de sus implicaciones.

Declaró (pues, así era su estilo) que la antropología social es una ciencia natural que toma como su ideal las ciencias físicas. Eso se desprende muy claramente de la versión biologicista del funcionalismo de Malinowski, y se desprende también con claridad del título de una de las obras póstumas de RadcliffeBrown: A Natural Science of Society de 1957, y éste había escrito ya en 1940 que "concibo la antropología social como la ciencia natural de la sociedad humana, es decir, la investigación de los fenómenos sociales por métodos esencialmente similares a los que se uti- 
lizan en las ciencias físicas y biológicas" (RadcliffeBrown, 1952: 188-189). Las dos escuelas son hijas del positivismo, pero mientras que Malinowski fundamenta su enfoque en la biología, Radcliffe-Brown busca su inspiración y su justificación en la sociología francesa, enfoque que nació en la obra de Augusto Comte en la década de 1830 y que llegó a su auge con la obra de Durkheim en las últimas décadas del siglo XIX y las primeras de este siglo. En eso se distingue rotundamente del enfoque establecido por Boas en los EE.UU., enfoque que exhibe una fuerte influencia del neo-kantianismo alemán.

\section{La tercera vía: la vía marxista}

La teoría marxista de la sociedad nace en el siglo de las luces como la historia universal o razonada, y se manifiesta ya en la teoría de los cuatro estadios (Meek, 1981). Inicialmente podemos preguntar "si existe una sociología marxista" (Goldmann, 1968), una pregunta que contesta rudamente Max Adler, el líder de los austromarxistas, hablando de Marx, "para él, y esa es una de sus principales ideas, Marx fue un sociólogo y, además, el fundador de la sociología. La obra de Marx fue antes que nada una obra sociológica”, y más adelante remata: "es Marx y no, como se piensa por lo regular, Augusto Comte, que es el verdadero fundador de la sociología" (Goldmann, 1968: 8).

En el pensamiento marxista de la época se han distinguido tres diferentes tendencias: la ortodoxia "científica”, representada por Plejanov y Karl Kautsky ${ }^{17}$, una sociología marxista neokantiana, representada principalmente por Vorländer (1904), y finalmente una sociología austromarxista, representada por Rudolf Hilferding, Otto Bauer y Max Adler (Goldmann, 1968: 4-6). Uno de los desarrollos de los austromarxistas fue el concepto de "cosmovisión", de origen kantiano ${ }^{18}$.

Una estación importante en el desarrollo occidental de la vía marxista es la herencia que empezó con la fundación del Instituto de Estudios Sociales ("Ins-

17 Karl Kautsky era un pensador marxista muy original: intentaba combinar las ideas de Marx con las de Darwin y, más notable todavía, planteaba que "si consideramos el mundo orgánico, antes que nada nos presenta una característica que lo distingue del mundo inorgánico - la finalidad" (Kautsky, 1906: 45).

18 Es interesante que este concepto, que durante muchos años pertenecía entre los conceptos de los antropólogos culturales de la escuela de Franz Boas (por cierto, neokantianos también), ha sido redescubierto y en la actualidad es el concepto de moda en la antropología mexicana. titut fur Socialforschung") que fue fundado en 1922 por Max Horkheimer y luego, con la incorporación de Teodor Adorno y el desarrollo de la "teoría crítica" y la "dialéctica negativa", sería "la Escuela de Frankfurt"19. Los dos pensadores podrían ser considerados, como Frederick LePlay en Francia, como los Marx'es de la burguesía, pues su pensamiento era altamente elitista y su orientación se destaca por incluir al psicoanálisis en su repertorio. Sus intereses giraban en torno a problemas que se pueden caracterizar como culturales, pero sus contribuciones netamente antropológicas fueron limitadas, pues prácticamente no prestó atención a la problemática de la alteridad.

Al concepto de la "gaya ciencia" inventada por el inmejorable optimista Friedrich Nietzsche, que se volvió loco en 1887, creó Theodor Adorno, el eterno pesimista que se quedaba cuerdo, el concepto complementario de la "ciencia melancólica", pues escribió Max Horkheimer, un pesimista más equilibrado, en su prólogo a la historia de la escuela que "la apelación a un mundo completamente otro (ein ganz Anderes), distinto a éste, tenía primariamente un ímpetu filosófico social. Finalmente condujo a una evaluación más positiva de ciertas tendencias metafísicas, porque el todo (empírico) es lo no verdadero (Adorno). La esperanza de que el horror terrenal no posea la última palabra es seguramente un deseo no científico". Los dos posteriores representantes más claros, Herbert Marcuse y Jürgen Habermas han sido, cada uno de su manera, los gurús de las rebeliones estudiantiles en 1968, respectivamente en Alemania y en Berkeley en los Estados Unidos.

En el marco de una sociología marxista tenemos que incluir a Georges Gurvitch, nacido en Rusia en 1894, que participó en la revolución de Octubre y conoció a Lenin, pero se peleó con los bolcheviques, por lo que se exilió y adquirió ciudadanía francesa en 1937, pasó la Segunda Guerra Mundial, de 1940 a 1945, en los Estados Unidos, para volver a Francia y ser nombrado profesor de sociología en la Sorbona en 1949. Georges Gurvitch, que bautizó su enfoque sociológico hiper-empirismo dialéctico, ha sido en gran medida olvidado en la tradición sociológica, hasta nos da la impresión de que más bien los antropólogos le han hecho

19 Existe una relación estrecha entre el instituto y el austromarxismo, pues Carl Grunberg, el segundo director del instituto, ha sido llamado "el padre del marxismo austriaco" (Léser, 1968: 177). Fue probablemente prudente rechazar bautizarlo "Instituto de Estudios Marxistas”, como fue sugerido en algún momento. 
caso: Lévi-Strauss señala ácidamente que "cada vez le entiende menos" (Lévi-Strauss, 1987: 121), mientras que Raymond Firth de una manera más simpática le otorga la paternidad de la expresión microsociología y macrosociología (Firth, 1944).

Noticias acerca de una sociología marxista practicada en los países socialistas antes de la caída del muro y del sistema socialista, las debemos antes que nada a Alvin Gouldner, a Peter Berger y a Tom Bottomore. Según Alvin Gouldner, alrededor de 1965 estaba surgiendo una tímida sociología en la Unión Soviética, sobre todo en Moscú, y Peter Berger introdujo en el oeste el conocimiento de la sociología en los países socialistas: la Unión Soviética, Checoslovaquia, Hungría, Polonia.

Con eso nos podemos mover hacia la antropología en la tradición marxista, de la cual quedó como un monumento la interpretación de Engels de Morgan en El origen del Estado, de la familia y de la propiedad privada. Son notables los dos antropólogos franceses Claude Meillassoux y Maurice Godelier por su determinación en aplicar la teoría marxista a las sociedades precapitalistas en clave estructuralista y, lo que es extraordinario entre los teóricos marxistas, basado en un sólido trabajo de campo, y tal vez tenemos que agregar a un tercero, a Emmanuel Terray.

Claude Meillassoux hizo el trabajo de campo para su tesis doctoral en la Costa de Marfil de julio 1958 a enero de 1959, sobre la economía de subsistencia de los gorro y bajo la dirección de Georges Balandier, y la publicó en 1964. Posteriormente se ha dedicado principalmente a estudiar la lógica y la racionalidad de la unidad doméstica y de producción en los modos de producción precapitalistas incrustados en formaciones capitalistas.

Maurice Godelier estudió originalmente filosofía, interesándose por la fenomenología de Husserl, pero se extraviaron sus intereses en varias direcciones que definirían sus futuros trabajos: por un lado, influenciado por Lévi-Strauss se interesó por el estructuralismo, por otro lado, extendió sus intereses filosóficos hacia la racionalidad, en particular en la economía, y finalmente atrajo un virus marxista, todo lo cual envolvió en el marco de la antropología. Su primer trabajo de campo lo hizo entre 1966 y 1969 entre los baruya en Nueva Guinea, de donde publicó varios artículos acerca de la economía, acerca de su moneda de sal y la circulación de las mercancías (Godelier, 1974: 267-298) y acerca de la ideología, la magia y el ritual, Godelier (1974:
355-365), y una monografía que retoma el concepto de Sahlins de "big men", que fue publicado hasta en 1982 (Godelier, 1986). Publicó en 1970 una pequeña obra erudita acerca de "la teoría marxista de las sociedades precapitalistas” (Godelier, 1977), con la discusión de una serie de asuntos medulares en la aplicación de la teoría marxista a las sociedades no occidentales. Antes ya había publicado una investigación de la "racionalidad e irracionalidad en economía", donde hizo una importante distinción entre "la racionalidad del agente" y "la racionalidad del sistema" (Godelier, 1967). Algunos de los temas medulares serían retomados en un texto acerca de "la antropología económica", donde define el objeto de estudio de esta disciplina, entre los formalistas y los sustantivistas (Godelier, 1974: 59-131). Del mismo año data una obra más amplia, donde intenta comprimir e ilustrar sus opiniones acerca de la antropología económica (Godelier, 1976), y en sus trabajos más recientes ha discutido problemas como la interpenetración de la base económica y la superestructura en lo material y lo ideal (Godelier, 1989), y el tema clásico de la reciprocidad, tratado originalmente por Marcel Mauss (Godelier, 1996).

\section{Un doble inicio: la etnometodología}

Tenemos un caso curioso en la creación de un estilo que en la sociología se llama etnometodología, pues surge al mismo tiempo en la antropología y en la sociología, pero prácticamente sin comunicación entre las dos disciplinas. En la sociología, "la etnometodología fue fundada en la década de los 1960 por Harold Garfinkel" (Alexander, 2000: 195), mientras que la correspondiente escuela en la antropología nació dentro de la antropología cultural norteamericana en los mismos años, por los esfuerzos de una serie de investigadores -Frake, Conklin, Goodenough, Tyler- que todos habían sido alumnos de Franz Boas o de sus seguidores. La biblia de cabecera de la etnociencia, o la antropología cognoscitiva como se llama también, es una antología que contiene artículos de todos los anteriores y que lleva el título poco original de "Cognitive Anthropology" (Tyler, 1969).

La etnometodología nació en 1967, con la publicación de "Studies in Ethnomethodology" de Harold Garfinkel, "durante una época de caóticos trastornos en las ciencias sociales, en las que el paradigma funcionalestructural parsoniano anteriormente dominante había 
pasado a la historia de la sociología" ${ }^{20}$, y su recepción en el ambiente sociológico fue tumultuosa y recibieron "el tributo de la crítica implacable" (Lukes, 1984: 2-3), y llegó a ser acusada de ser "un método sin sustancia” (Coser, 1975), por lo que Garfinkel unos años más tarde declaró que "el término etnometodología se había convertido en una consigna con vida propia" (Garfinkel, 1974: 18). Garfinkel, el solitario creador de la etnometodología, había sido alumno de Talcott Parsons y su creación fue en gran medida una protesta contra la teoría sociológica que este había desarrollado, a partir de 1946 como director del Departamento de Relaciones Sociales de la Universidad de Harvard y en la forma de una unificación de las perspectivas de la psicología, la sociología y la antropología como ya lo había diseñado Parsons en The Structure of Social Action como una teoría voluntarista de la acción (Parsons, 1937); es evidente que la inspiración a la acción social proviene de Max Weber, cuya obra Parsons había traducido al inglés.

Si nos vamos al campo antropológico, encontramos una serie de coincidencias en la creación de una antropología cognoscitiva. Un precursor importante de esta disciplina fue James P. Spradley, quien decidió intentar entender "desde dentro" la vivencia de lo que el llama una "subcultura", es decir lo que en otros contextos ha sido llamado una "cultura subalterna" y que para Spradley representa un modo de adaptación, en su caso la vivencia de los vagabundos en una ciudad en los Estados Unidos.

El organizador de la antropología cognoscitiva define sus objetivos así: "la antropología cognoscitiva intenta esencialmente contestar dos preguntas: ¿cuáles son los fenómenos materiales que les son significativos a las personas de una cultura dada? y ¿de qué manera organizan estos fenómenos? Entre sí las culturas no solamente varían en su organización de fenómenos materiales, también son diferentes en la selección de qué fenómenos materiales organizar. La gente de diferentes culturas no reconocen los mismos fenómenos como relevantes, no obstante que los mismos fenómenos mate-

20 Heritage, 1990: 291. Casi desde el inicio de la cátedra de Parson, Garfinkel fue alumno suyo, y muy pronto empezó a publicar artículos donde poco a poco se empieza a perfilar su posición, que luego se manifestaría en su etnometodología: "Cuando Garfinkel escribió el lúcido ensayo, aún no era un "etnometodólogo”. Aún no había iniciado la escuela que lideraría desde la década de los 1960, y aún no había inventado un nombre para distinguir esta escuela del resto de la sociología. En esa época Garfinkel era simplemente un alumno de Schutz que también era alumno de Parsons" (Alexander, 2000: 208). riales estén presentes en todos los casos desde un punto de vista externo" (Tyler, 1969: 3).

En una de las múltiples redefiniciones del concepto de cultura, tenemos el siguiente resultado: "la cultura de una sociedad abarca todo lo que hay que saber o creer para poder operar de una manera que les sea aceptable a los miembros y poderlo ejecutar en cualquier rol, que ellos mismos aceptan como adecuado para uno mismo" (Goodenough, 1957: 167-168).

En la creación de estas dos escuelas, respectivamente en la sociología y en la antropología, dos cosas llaman la atención: en primer lugar, que en los rasgos generales son virtualmente idénticas, ambas son intentos por combinar las virtudes y la fuerza del enfoque científico y positivista con las ventajas y la comprensión que otorga el enfoque fenomenológico; en segundo lugar, que se desarrollan casi sin atención y referencias mutuas: en un resumen de la etnometodología se menciona la antropología cognoscitiva solamente una vez (Heritage, 1990: 291), en una nota a pie de página, y en la Biblia de la antropología cognoscitiva ni siquiera es mencionada la etnometodología (Tyler, 1969). Un tercer rasgo es que ambas parecen, en cierto sentido, un animal con cuatro patas traseras, pues, en su afán por combinar lo objetivo y lo subjetivo amontonan los dos niveles sin crear ninguna articulación.

\section{La postmodernidad y el postmodernismo}

Como el romanticismo nació en protesta contra el pensamiento de la Ilustración, así también el postmodernismo nació en protesta contra las más burdas versiones del positivismo, también en su forma de neopositivismo, con su destierro de la metafísica y cualquier tipo de ambigüedad creativa, junto con su alabanza del método científico. Y el postmodernismo tiene bastante relación con el espíritu del romanticismo ${ }^{21}$.

Más precisamente, "el surgimiento de la antropología posmoderna es, en sentido estricto, un proceso de transformación experimentado por una de las tantas corrientes internas de la disciplina, la llamada antropo-

21 Como bandera del postmodernismo podría servir la tipología de animales creada por Jorge Luis Borges: "los animales se dividen en a) pertenecientes al emperador, b) embalsamados, c) amaestrados, d) lechones, e) sirenas, f) fabulosos, g) perros sueltos, h) incluidos en esta clasificación, i) que se agiten como locos, j) innumerables, k) dibujados con un pincel de finísimo pelo de camello, l) etcétera, m) que acaban de romper el jarrón, n) que de lejos parecen moscas” (Borges, 1960: 42). 
logía interpretativa. Tras una fase tibia de antropología simbólica en las décadas de 1960 y 1970, y luego de un falso arranque bajo las banderas de la fenomenología (demasiado escolásticas, trascendentales y solemnes para los tiempos que corren), los interpretativos hallaron en un posmodernismo que algunos refutarán predigerido y fragmentario su marco más afín. A despecho de la naturalidad con la que los posmodernos asumen su propia transición en el relevo de las modas, la polémica se ha desarrollado en torno del movimiento es una de las más tensas y delicadas de la historia disciplinar; no hay más que asomarse a las revistas antropológicas recientes: sucede casi como si todo otro tema hubiera sido postergado en espera de su resolución" (Reynoso, 1991: 11).

El postmodernismo no fue un evento que de manera repentina vino a cambiar las ciencias sociales, convirtiéndolas hasta cierto punto en humanidades, fue más bien la culminación de una serie de tensiones en las mismas ciencias sociales, que tuvieron sus orígenes en la fenomenología (en su turno heredera de todo un estilo de pensamiento antipositivista y a veces anticientífica) y su locus lógico en la antropología cultural norteamericana (y también en la etnología francesa, de carácter muy especulativa y con un desarrollo de técnicas etnográficas muy tardía). En este sentido, el evento fundacional fue el Congreso en Santa Fe en 1984, del cual salió la Biblia de la antropología postmoderna, "Writing Culture" de James Clifford \& George Marcus. Como fruto concreto distingue Carlos Reynoso tres líneas de desarrollo en la antropología: 1) Una meta-etnografía o bien meta-antropología en la que participan James Clifford, George Marcus, Dick Cushman, Marilyn Strathern, Robert Thornton y Michael Fischer, entre otros, y en algún momento también Clifford Geertz; 2) Una etnografía experimental, con Vincent Crapanzano, Kevin Dwyer y Paul Rabinow; 3) Una tercera corriente, la más radical y tal vez nihilista que proclama la muerte de la ciencia y determinada manera de escribir antropología, que es más bien disolvente, con Stephen Tyler y Michael Taussig (Reynoso, 1991: 28). Hay que señalar que la situación que describe Carlos Reynoso es ya de hace alrededor de veinte años; sin embargo, pienso que sus observaciones siguen con validez como punto de partida.

Se nota que todos los antropólogos postmodernos aquí citados son extremadamente idealistas (lo que podría tener que ver con sus orígenes en la antropología cultural norteamericana y su relación con la fenome- nología), tal vez con la excepción de Tyler y Taussig, que en todo son atípicos, pues de nuevo son los únicos que no han sido alumnos de Clifford Geertz, quien ocupa un curioso lugar en este movimiento, primero como el padre del postmodernismo y luego como víctima de un parricidio.

Encontramos el mismo movimiento postmoderno en la sociología. Como el ejemplo más preclaro podemos mencionar la sociología de Michel Maffesoli, que es antes que nada una sociología de la sensibilidad y la irracionalidad, en lo que hay algo de paradójico, pues la sociología de Émile Durkheim, cuya cátedra ocupa Maffesoli, era netamente una sociología de la racionalidad y la razón, excluyendo tanto la sensibilidad como la irracionalidad. Y sigue la paradoja, pues como la sociología de Durkheim era una sociología de la armonía y la integración, tres de los libros tempranos de Maffesoli giran en torno a todo lo contrario, la dominación y el conflicto (La lógica de la dominación de 1976, La violencia fundacional de 1978 y La violencia totalitaria de 1979), mientras que en su Compendio de sociología, con el título de Conocimiento ordinario, presenta su programa en cinco hipótesis, en las cuales intenta "exponer lo que podría llamarse las premisas epistemológicas de un manual de sentido-comunologia": "la crítica del dualismo esquemático", "la forma", "la sensibilidad relativista", "la investigación estilística" y "el pensamiento libertario" (Maffesoli, 1993: 35, 11, 13-34). Algo más nos revela el libro acerca del posmodernismo de Maffesoli: una de las características de este estilo de pensar es su afinidad con la expresión literaria, y la introducción del libro empieza con una cita de Marcel Proust, uno de los pilares de la modernidad que dio pie al postmodernismo: "y cuando usted me habla de una catedral, no puedo dejar de emocionarme esa intuición que le permite adivinar lo que no le he dicho a nadie y que escribo por primera vez, que quise darle a cada parte de mi libro el título: portal, vitrales del ábside, etc. ... para responder por adelantado a la tonta crítica que me hacen de que la falta construcción a mis libros, cuyo único mérito, como le mostraré, es la solidez de sus menores partes" (Maffesoli, 1993: 9, citando a Marcel Proust), así como que la siguiente parte es introducido de una cita de Stendhal, de su novela romántica Armance, y termina con una cita de Baudelaire, otro autor emblemático que marca la confluencia de la modernidad y el postmodernismo.

Es mi impresión que el postmodernismo nació, brilló y se apagó, es un movimiento que ya pertenece 
a los textos de la historia de las ciencias o, más diplomáticamente, las disciplinas. Pero al mismo tiempo es mi impresión que el mencionado y abandonado postmodernismo sí nos dejó un legado y un reto. Carecía de lealtad social, era un movimiento sumamente arrogante y elitista. Señaló en su momento una socióloga mexicana que "la postmodernidad ha llegado a México. Ha llegado a través de la reflexión de los intelectuales; más que un sentimiento generalizado y una práctica cotidiana de la mayoría, es una problemática filosófico-política que tiene una existencia fundamentalmente discursiva. Mientras algunos políticos señalan la falta de modernidad de la estructura socio-política de México, y se genera un amplio debate sobre la idea misma y la implementación posible de lo moderno, los intelectuales leen, estudian y discuten acerca de las características de la postmodernidad: un proceso que si bien en algunos aspectos tiene puntos de contacto con la realidad mexicana y latinoamericana, es sin embargo propiamente europeo y estadounidense. América Latina no ha sido, no es, globalmente moderna. ¿Puede, por lo tanto, considerarse postmoderna?" (Girola, 1988: 257).

\section{Conclusiones: perspectivas futuras}

Un argumento central a través de todo el presente texto ha sido que la antropología y la sociología son, en esencia, la misma cosa pero de diferentes maneras. Quisiera reservarme el derecho a limitarme a una conclusión muy poco concluyente y de un carácter sumamente provisional y volver a discutir las articulaciones muy particulares de las dos disciplinas aquí tratadas - la antropología y la sociología — con la herencia marxista.

Un rasgo compartido es que los antropólogos parecemos ser una especie en peligro de extinción, pero siempre me sorprende que los sociólogos, en efecto, se quejan más de sus precarias perspectivas de empleo y remuneración, así que en eso estamos juntos.

Las dos disciplinas - la antropología con su nombre tan pretencioso y la sociología con su feo nombre compuesto- comparten un rasgo, aunque en grado diferente: ambos prometen conocimientos universales o casi universales, pero a la hora de la verdad nos presentan paradigmas que son nacionales, a veces hasta nacionalistas. No cuesta mucho esfuerzo distinguir una antropología cultural norteamericana de una an- tropología social británica o de una etnología francesa, y hasta de una antropología mexicana, de igual manera podemos distinguir entre las correspondientes sociologías. Es revelador que un libro tan grande, general y amplio, como es Las teorías sociológicas desde la Segunda Guerra Mundial (Alexander, 2000), de más de 300 páginas y que en cinco capítulos trata la teoría sociológica de Talcott Parsons — en efecto toda la arquitectura del libro gira en torno a la teoría de Talcott Parsons- ni siquiera menciona el nombre de Pierre Bourdieu, y no encontramos a Radcliffe-Brown, para quien la antropología era sociología comparativa o a Malinowski, quien a fin de cuentas fue uno de los profesores de Talcott Parsons.

Un tema de discusión es la cuestión de qué tanto cambia este provincialismo la existencia de Internet con su más rápida y amplia comunicación.

Para volver a la promesa de algún tipo de conclusión, quisiera partir del título de dos libros, por cierto muy diferentes: Sociología de la cultura, de dos científicos cubanos (Basail Rodríguez y Alvarez Durán, comps., 2006), y Sociología cultural, de un erudito sociólogo norteamericano (Alexander, 2006). Partiendo de estos dos títulos podemos preguntarnos: ¿qué es lo que le faltaba a cada una de estas dos disciplinas y las llevó a una fusión?

En lo referente a la interdisciplinariedad, salta a la vista que la separación de la antropología y la sociología es una separación con pocos fundamentos, y algunos de ellos de poco valor, pues las disciplinas se manifiestan en la docencia y se mezclan y diluyen en la investigación, lo que es otro tema de discusión, que pone en peligro la existencia de instituciones de educación superior sin investigación.

\section{Referencias bibliográficas}

AleXander, Jeffrey C. (2000). Las teorías sociológicas desde la Segunda Guerra Mundial, Barcelona, Gedisa.

Alexander, Jeffrey C. (2006). Sociología cultural. Formas de clasificación en las sociedades complejas, Barcelona, Anthropos.

Basail Rodríguez y ÁluVArez Durán, comps. (2006). Sociología de la cultura, I-II, Habana, Editorial Félix Varela.

Borges, Jorge Luis (1960). Otras inquisiciones, Buenos Aires, Emecé.

Cuvier, Georges (1825). Discours sur les révolutions de la surface du Globe, Paris. 
Dibie, Pascal (1999). La etnología de la alcoba, Barcelona, Gedisa.

Durkheim, Émile (1988). "Las reglas del método sociológico”, Barcelona, Alianza.

Firth, Raymond (1974). "El lugar de Malinowski en la historia de la antropología", en R. Firth, ed.: Hombre y cultura. La obra de Bronislaw Malinowski, México, Siglo XXI, 1974: 227-248.

Girola, Lidia (1988). "Particularismo y posmodernidad", Sociologica, Año 3, No. 7/8: 257-269.

Godelier, Maurice (1967). "Racionalidad e irracionalidad en economía”, México, Siglo XXI.

Godelier, Maurice (1974). "Economía, fetichismo y religión en las sociedades primitivas", México, Siglo XXI.

Godelier, Maurice (1974). Rationalité \& irrationalité en économie, I-II, París, Maspero.

Godelier, Maurice (1976). "Antropología y economía”, Barcelona, Anagrama.

Godelier, Maurice (1977). "Teoría marxista de las sociedades precapitalistas", Barcelona, Laia.

Godelier, Maurice (1986). "La producción de grandes hombres. Poder y dominación masculina entre los baruya de Nueva Guinea" Barcelona, Akal.

Godelier, Maurice (1989). "Lo ideal y lo material. Pensamiento, economías, sociedades", Madrid, Taurus.

Godelier, Maurice (1996). "El enigma del don. Dinero, regalos, objetos natos", Barcelona, Paidós Ibérica.

Goldmann, Lucien (1968). "Is there a Marxist Sociology?", International Socialism, No. 34, Otońo 1968: 13-21.

GonzÁlez Noriega, Santiago (1988). "Introducción. El hecho social en Durkheim”, en Emile Durkheim: Las reglas del método sociológico, Barcelona, Alianza, 1988: 7-28.

Goodenough, W. H. (1957). Cultural Anthropology and Linguistics, Georgetown University Monograph Series on Language and Linguistics No. 8.

Heritage, John C. (1990). "Ethnomethodology", en Anthony Giddens, ed.: La teoría social, hoy, México, Alianza/CNCA, 1990: 290-350.

Kautsky, Karl (1906). Ethics and the Materialist Conception of History, Berlín.

Korsbaek, Leif \& Marcela Barrios Luna (2010). "La antropología en Cuba”, en la revista Cuicuilco, Vol. 16, No. 46: 11-34.

Leser, Norbert (1968). Zwischen Reformismus und Bolschewismus. Der Austromarxismus als Theorie und Praxis, Viena, Frankfurt \& Zurich.

LÉvi-Strauss, Claude (1987). Antropología estructural, Barcelona, Paidós.
Lukes, Steven (1984). Émile Durkheim. Su vida y su obra, Madrid, Siglo XXI.

Maffesoli, Michel (1993). El conocimiento ordinario. Compendio de sociología, México, Fondo de Cultura Económica.

Malinowski, B. (1942). "A New Instrument for the Interpretation of Law - especially Primitive" (Reseńa de Hoebel \& Llewellen: "The Cheyenne Way: Conflict and Case Law in Primitve Jurisprudence”), Yale Law Review, Vol. 51: 1237-1254.

Malinowski, B. (1947). "Freedom and Civilization", London.

Malinowski, Bronislaw (1912). "The Economic Aspect of the Intichiuma Ceremonies", en Festskrift tillegnad Edward Westermarck I anledning av hans femtiaarsdag den 20. November 1912, Universidad de Helsinki.

Malinowski, Bronislaw (1931). "Culture", Encyclopedia of the Social Sciences, New York, Vol. IV: 621-646.

MaLINOwSKI, Bronislaw (1934). "Introduction" a H. Ian Hogbin: Law and Order in Polynesia, London, 1934: XVII-LXXII.

Malinowski, Bronislaw (1975). Los argonautas de Pacifico occidental, Bacelona, Península.

Meex, Ronald (1981). "Los orígenes de la ciencia social. El desarrollo de la teoría de los cuatro estadios", México, Siglo XXI.

Natanson, Maurice (1995). "Introducción", en Alfred Schutz: El problema de la realidad social, Buenos Aires, 1995: 15-32.

Panoff, Michel (1974). Malinowski y la antropologia, Barcelona, Labor.

Parsons, Talcott (1937). The Structure of Social Action, New York, The Free Press.

Piddington, Ralph (1974). "La teoría de las necesidades de Malinowski”, en R. Firth, ed.: Hombre y cultura. La obra de Bronislaw Malinowski, México, Siglo XXI, 1974: 39-62.

Radcliffe-Brown, A. R. (1952). Structure and Function in Primitive Society, London, Routledge \& Kegan Paul.

Radcliffe-Brown, A. R. (1957). A Natural Science of Society, Chicago, University of Chicago Press.

Reynoso, Carlos (1991). El surgimiento de la antropología posmoderna, Barcelona, Gedisa.

Rodríguez CePeda, Enrique (1990). "Introducción” a Luis Vélez de Guevara: El diablo cojuelo, México, Rei, 1990: 11-62.

Schutz, Alfred (1953). "El sentido común y la interpretación científica de la acción humana", en Alfred Schutz: "El problema de la realidad social", Buenos Aires, Amorrortu, 1995: 35-70. 
Spengler, Oswald (1978). La decadencia del Occidente. Bosquejo de morfología de la historia universal (org. I: 1918, II; 1922), Madrid, Espasa-Calpe, 1978.

Steinhoff, M. (1924-25). "Die Form als soziologische Grundkategorie bei Georg Simmel”, Kölner Vierteljahrschrift für Soziologie, Vo. 4, 1924-25: 215-259.
Timasheff, Nicolás S. (1992, 16a. reimpresión). La teoría sociológica, México, Fondo de Cultura Económica.

Tyler, Stephen, editor (1969). Cognitive Anthropology, Berkeley, University of California Press. 